\title{
Parameter pengukuran ventrikel kiri (1) Update rekomendasi tahun 2015 dari American Society of Echocardiography dan European Association of Cardiovascular Imaging
}

\author{
Ario Suryo
}

$\mathrm{P}$ emeriksaan dan pengukuran dimensi Ventrikel kiri (Vki) merupakan salah satu parameter utama dalam pencitraan kardiovaskular dalam hal ini ekokardiografi. Oleh karena itu diperlukan rekomendasi untuk menyamakan metodologi pengukurannya. American Society of Echocardiography (ASE) dan European Association of Echocardiography ( saat ini menjadi European Association of Cardiovascular Imaging/ EACVI) telah mengeluarkan rekomendasi yang diterbitkan sejak tahun 2005. Dikarenakan kemajuan teknologi di bidang ekokardiografi yang cukup pesat, maka diperlukan pembaharuan terhadap rekomendasi tersebut untuk mengakomodir teknik-teknik baru seperti 3 Dimensi ekokardiografi (3DE) dan pengukuran deformation imaging yang sudah banyak dipakai dalam praktek klinis sehari-hari. Tulisan ini merangkum rekomendasi terbaru yang dikeluarkan kedua asosiasi tersebut baru-baru ini.

\section{Pengukuran Ventrikel kiri (Vki)}

Parameter ini adalah yang paling umum digunakan untuk menggambarkan ukuran rongga Vki termasuk

\section{Alamat Korespondensi}

dr. Ario Suryo, Departemen Kardiologi dan Kedokteran Vaskular FKUI, dan Pusta Jantung Nasional Harapan Kita, Jakarta. E-mail: arioskoe@yahoo.com dimensi internal (linear) dan volume. Pengukuran umumnya dilaporkan pada fase diastolik dan akhir sistolik, yangkemudian digunakan sebagai parameter fungsi global Vki. Pengukuran ruang Vki harus dilaporkan setelah di indeks terhadap luas permukaan tubuh (Body Surface Area /BSA) untuk mengurangi pengaruh perbedaan ukuran tubuh pada individu yang diperiksa.

\section{Pengukuran linier}

Disarankan agar pengukuran linear internal Vki dan dindingnya dilakukan pada pandangan parasternal sumbu panjang (PLAX). Pengukuran dilakukan secara hati-hati dengan melakukan pengukuran dengan sumbu panjang Vki dan diukur pada atau tepat di bawah ujung katup mitral. Dalam hal ini, elektronik kaliper harus diposisikan pada pertemuan antara dinding miokard dengan rongga dan pertemuan antara dinding dengan perikardium. Dimensi internal dapat diperoleh dengan menggunakan metoda dua dimensi ekokardiografi (2DE) dan modalitas M-mode. Meskipun pengukuran linear yang diperoleh dari 2DE lebih disukai untuk menghindari bagian miring dari Vki.

\section{Pengukuran volumetrik}

Volume Vki diukur menggunakan metode 2DE atau ekokardiografi 3Dimensi (3D)E. Perhitungan volume yang didapatkan dari pengukuran secara linear mungkin 

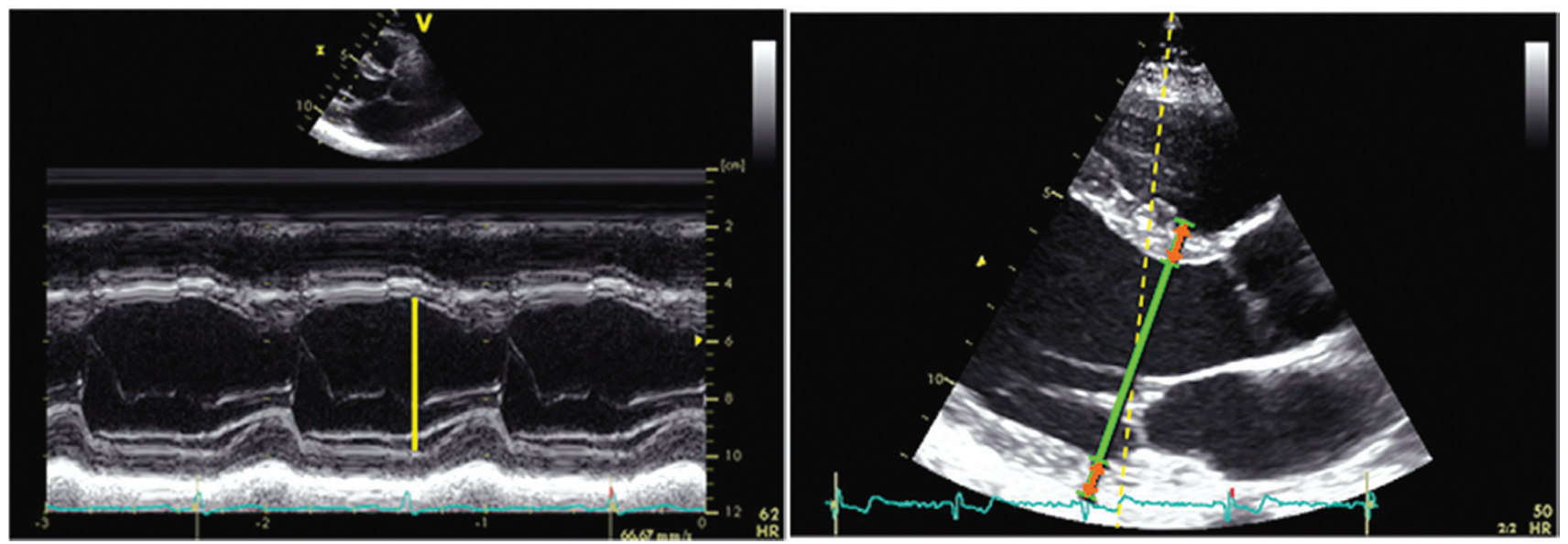

Gambar 1. Metode linear dan 2DE

tidak akurat karena mereka bergantung pada asumsi bahwa Vki bentuk geometris seperti ellipsoid, asumsi ini tidak berlaku dalam berbagai kelainan jantung. Dengan demikian, metode Teichholz dan Quinones untuk menghitung volume Vki dari dimensi linear tidak lagi direkomendasikan untuk penggunaan klinis.

Pengukuran volumetrik biasanya didasarkan pada penelusuran dari antarmuka antara miokardium yang bersinggungan dengan rongga Vki. Pada potongan setinggi katup mitral, kontur Vki diakhiri dengan menghubungkan dua titik dari anulus mitral menggunakan garis lurus. Panjang Vki didefinisikan sebagai jarak antara garis dari ini apikal Vki yang dengan titik potong dengan garis pada tingkat anulus mitral. Jarak terpanjang yang didapatkan dari pandangan 2 ruang (2ch) dan pandangan 4 ruang (4ch) Vki dianjurkan untuk di gunakan.

Volume Vki harus diukur dari padangan $4 \mathrm{Ch}$ dan 2Ch untuk mendapatkan ukuran maksimal Vki secara maksimal sambil menghindari foreshortening Vki yang menghasilkan nilai yang lebih rendah dari yang sebenarnya. Pengambilan pandangan ini sebaiknya dilakukan dengan kedalaman yang dikurangi sehingga lebih pandangan lebih ter fokus pada rongga LV akan mengurangi kemungkinan foreshortening dan meminimalkan kesalahan dalam penelusuran
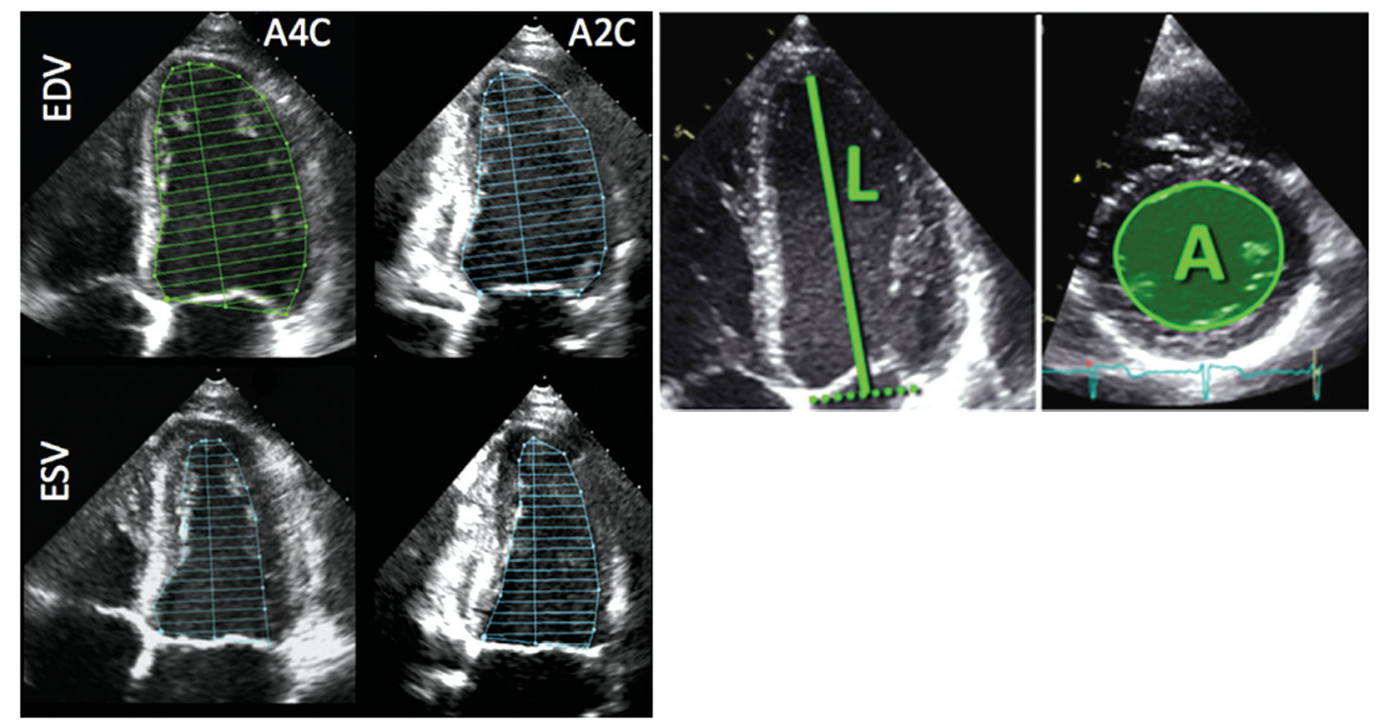

Gambar 2. Metode biplane disk Simpson dan area length 
perbatasan endokardium. Pemakaian zat kontras (apabila tersedia) harus digunakan apabila diperlukan untuk memperjelas batas endokardial apabila terdapat dua atau lebih area dengan delineasi yang buruk untuk divisualisasikan dalam pandangan apikal.

Metode perhitungan volume 2DE yang paling sering digunakan adalah metode biplane dari penjumlahan lempeng Vki (Simpson yang dimodifikasi), yang merupakan metode 2DE yang direkomendasikan oleh konsensus ini (Tabel 1).

Sebuah metode alternatif untuk menghitung volume Vki ketika batas endokardial apical Vki sulit dinilai sehingga sulit mendapatkan hasil akurat adalah dengan menggunakan metode area length dimana Vki diasumsikan berbentuk seperti peluru. Area pada daerah pertengahan Vki diukur dari pandangan cross sectional (SAX), kemudian panjang Vki diambil dari pandangan 4Ch dengan menarik garis dari titik anulus mitral sampai ke puncak di apical Vki. (Tabel 1). Kelemahan dari metode ini adalah asumsi Vki seperti bentuk peluru tidak selalu berlaku. Salah satu keuntungan dari 3D pengukuran volume yang ekokardiografi adalah bahwa mereka tidak mengandalkan asumsi geometris. Pada pasien dengan kualitas gambar yang baik, 3D pengukuran ekokardiografi akurat dan mudah direproduksidan karena itu harus digunakan bila tersedia (pengukuran dengan metode 3DE tidak dibahas mendalam dalam tulisan ini).

\section{Fungsi global sistolik Vki}

Fungsi global Vki biasanya dinilai dengan mengukur perbedaan antara nilai akhir diastolik dan akhir sistolik dari satu dimensi, Parameter 2DE, atau 3DE kemudian dibagi dengan nilai akhir diastolik nya. Untuk ini, fase akhir diastolik sebaiknya didefinisikan sebagai frame pertama setelah penutupan katup mitral atau frame dalam siklus jantung di mana masing-masing dimensi atau pengukuran volume VKi terbesar. Fase akhir sistolik yang terbaikdidefinisikan sebagai frame setelah penutupan katup aorta atau frame dimana dimensi jantung atau volumenya yang terkecil. Pada pasien dengan irama jantung yang teratur, penentuan waktu bukaan katup dan penutupannya dapat menggunakan modalitas M-mode echocardiography, gambaran Pulsed Wave Doppler (PWD) atau Continous Wave Doppler (CWD) sehingga penentuan interval waktu ventrikel menjadi lebih akurat.

\section{Frational Shortening (FS)}

Fractional Shortening bisa didapat dari modalitas M-mode atau yang lebih disukai dengan pengukuran secara linear dari 2DE. Mendapatkan fungsi global Vki dengan menggunakan parameter linear kadang kala bermasalah ketika ada kelainan gerakan dinding miokardial dikarenakan penyakit jantung koroner atau kelainan konduksi. Pada pasien hipertensi tanpa komplikasi, obesitas atau penyakit jantung katup, perbedaan regional seperti itu jarang didapatkan pada mereka yang tidak didapatkan tanda-tanda infark miokard sebelumnya. Oleh karena itu parameter ini dapat memberika informasi yang berguna dalam studi-studi klinis. Pada pasien dengan ukuran basal Vki normal namun pada bagian tengah dan distal Vki mengalami pelebaran, volume Vki akan menjadi penanda ukuran Vki yang lebih baik daripada menggunakan pengukuran dimensi secara linier yang diukur pada basal Vki.

\section{Ejection Fraction (EF).}

Ejection Fraction dihitung dari volume diastolic akhir Vki (EDV) dan volume sistolik akhir Vki (ESV), dengan menggunakan rumus berikut:

\section{$\mathrm{EF}=(\mathrm{EDV} \cdot \mathrm{ESV}) /=\mathrm{EDV}$}

Volume Vki bisa didapatkan baik dari 2DE atau 3DE, seperti telah dijelaskan di atas (bagian 1.2). Metode biplane lempeng (modified Simpson) adalah metode $2 \mathrm{D}$ yang saat ini dianjurkan untuk menilai EF Vki oleh konsensus pada komite ini. Pada pasien dengan kualitas gambar yang baik, pengukuran EF berbasis 3DE cukup akurat dan sebaiknya digunakan apabila metode ini tersedia dan memungkinkan.

\section{Global Longitudinal Strain (GLS)}

Regangan (strain) Lagrangian didefinisikan sebagai perubahan panjang dari suatu objek dalam arah tertentu relatif terhadap panjang pada posisi awalnya:

Strain $(\%)=(\mathrm{Lt}-\mathrm{LO}) / \mathrm{LO}$,

Dimana Lt adalah panjang pada waktu $\mathrm{t} 1$, dan L0 adalah panjang awal pada saat 0 . Penilaian fungsi global Vki berbasis strain yang paling sering digunakan 
Jurnal Kardiologi Indonesia

Tabel 1.Nilai normal untuk dimensi Vki dan volume Vki berdasarkan jenis kelamin

\begin{tabular}{|c|c|c|c|c|}
\hline \multirow[b]{2}{*}{ Parameter } & \multicolumn{2}{|c|}{ Male } & \multicolumn{2}{|c|}{ Female } \\
\hline & Mean $\pm S D$ & 2-SD range & Mean $\pm S D$ & 2-SD range \\
\hline \multicolumn{5}{|l|}{ LV internal dimension } \\
\hline Diastolic dimension $(\mathrm{mm})$ & $50.2 \pm 4.1$ & $42.0-58.4$ & $45.0 \pm 3.6$ & $37.8-52.2$ \\
\hline Systolic dimension (mm) & $32.4 \pm 3.7$ & $25.0-39.8$ & $28.2 \pm 3.3$ & $21.6-34.8$ \\
\hline \multicolumn{5}{|l|}{ LV volumes (biplane) } \\
\hline $\operatorname{LVEDV}(\mathrm{mL})$ & $106 \pm 22$ & $62-150$ & $76 \pm 15$ & $46-106$ \\
\hline $\operatorname{LVESV}(\mathrm{mL})$ & $41 \pm 10$ & $21-61$ & $28 \pm 7$ & $14-42$ \\
\hline \multicolumn{5}{|c|}{ LV volumes normalized by BSA } \\
\hline $\operatorname{LV} \operatorname{EDV}\left(\mathrm{mL} / \mathrm{m}^{2}\right)$ & $54 \pm 10$ & $34-74$ & $45 \pm 8$ & $29-61$ \\
\hline $\operatorname{LVESV}\left(\mathrm{mL} / \mathrm{m}^{2}\right)$ & $21 \pm 5$ & $11-31$ & $16 \pm 4$ & $8-24$ \\
\hline LV EF (biplane) & $62 \pm 5$ & $52-72$ & $64 \pm 5$ & $54-74$ \\
\hline
\end{tabular}

Tabel 2. Nilai normal untuk volume Vki, EF berdasarkan jenis kelamin dan usia

\begin{tabular}{|c|c|c|c|c|c|c|c|c|c|c|c|c|c|c|c|c|c|c|c|c|}
\hline \multirow[b]{3}{*}{ renumber } & \multicolumn{4}{|c|}{$A g=2 a \approx y$} & \multicolumn{4}{|c|}{ Agesamy } & \multicolumn{4}{|c|}{ Agetame $y$} & \multicolumn{4}{|c|}{$A=30-\infty$} & \multicolumn{4}{|c|}{$A=\infty$} \\
\hline & \multicolumn{2}{|r|}{ no } & \multicolumn{2}{|r|}{ Tande. } & \multicolumn{2}{|r|}{ Met } & \multicolumn{2}{|r|}{ rande. } & \multicolumn{2}{|r|}{ Mn } & \multicolumn{2}{|r|}{ ratude. } & \multicolumn{2}{|r|}{ mat } & \multicolumn{2}{|r|}{ tande. } & \multicolumn{2}{|r|}{$m=$} & \multicolumn{2}{|r|}{ Nam $=$} \\
\hline & $n N$ & $\min =50$ & $n$ & $\operatorname{Mm} m=50$ & $n v$ & $\operatorname{man}=50$ & $n v$ & $\operatorname{man}=50$ & $n$ & $\operatorname{man}=50$ & $n s$ & $\operatorname{man}=50$ & $n$ & $\operatorname{man}=50$ & $n N$ & $\operatorname{Mn} m=50$ & $n$ & $\operatorname{man}=\infty$ & $n$ & $\operatorname{man}=50$ \\
\hline \multicolumn{21}{|l|}{ Reical two enamber view } \\
\hline LV EF ( $)$ & 14 & $\theta=4$ & 16 & $Q=6$ & 27 & $\theta=5$ & 18 & $66=5$ & $\$ 4$ & $Q=6$ & 223 & $63=6$ & 21 & $e x=8$ & 200 & $e 4=6$ & 34 & $63=6$ & 36 & $\boldsymbol{\theta}=6$ \\
\hline LV EOV $(-L)$ & 14 & $122=18$ & 16 & $88=21$ & 27 & $111=27$ & 18 & $88=14$ & 34 & $121=25$ & 223 & $20=22$ & 201 & $180=302$ & 200 & $87=23$ & 34 & $88=22$ & 36 & $\Theta=12$ \\
\hline LV ESV (mL) & 14 & $A=7$ & 16 & $33=10$ & 27 & $e=11$ & 18 & $31=7$ & 14 & $\$ 8=14$ & 223 & $34=11$ & 21 & $48=162$ & 290 & $32 \pm 11$ & 34 & $32=8$ & 38 & $22=6$ \\
\hline \multicolumn{21}{|c|}{ Acical Sou chanber vaw" } \\
\hline LV ESV (mL) & 247 & $51 \pm 13$ & 274 & $30=11$ & 363 & $59 \pm 14$ & $A 8$ & $37 \pm 19$ & 236 & $50 \pm 16$ & 383 & $34 \pm 12$ & $\infty$ & $f=16$ & 183 & $33 \pm 12$ & 29 & $45=2$ & 18 & $x \neq 7$ \\
\hline \multicolumn{21}{|c|}{ 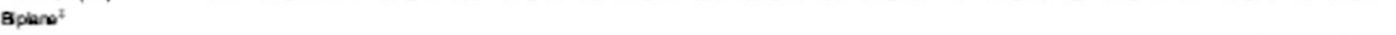 } \\
\hline LVEF $Q 6)$ & 29 & $Q=5$ & 30 & $6=4$ & 34 & $e+1=4$ & 34 & $63=4$ & 45 & $\theta=5$ & 82 & $64=4$ & 6 & $e x=5$ & 188 & $64=5$ & 38 & $63=5$ & 48 & $x=6$ \\
\hline LVEOV (nL) & 29 & $198=25$ & 39 & $g=18$ & 34 & $144=22$ & 34 & $82=13$ & 45 & $100=20$ & 82 & $n \geq \pm 13$ & 6 & $101=21$ & 198 & $73=14$ & 38 & $28=21$ & 48 & $E=11$ \\
\hline LV ESV (mL) & 29 & $\$ 8=11$ & 39 & $32 \pm 8$ & 34 & $\mu \pm 10$ & 34 & $39 \pm 6$ & 45 & $41=10$ & 82 & $28 \pm 6$ & 8 & $36 \pm 9$ & 196 & $28 \pm 6$ & 38 & $36=9$ & 48 & $24=6$ \\
\hline LV stroke volume (nt) & 29 & $73 \pm 17$ & 39 & $85 \pm 12$ & 34 & $\Theta=15$ & 34 & $52 \pm 8$ & 45 & $\infty \pm 12$ & 82 & $49 \pm 9$ & 55 & $64 \pm 15$ & 198 & $46 \pm 10$ & 38 & $62=x$ & 48 & $4=8$ \\
\hline \multicolumn{21}{|c|}{ Reical sou chamber vaw' } \\
\hline LV EOV (rums) & 247 & $x=14$ & 274 & $e s=13$ & 363 & $Q=13$ & 48 & $50=13$ & 295 & $\infty=13$ & 383 & $50=11$ & $\boldsymbol{x}$ & $90 \pm 13$ & $1 e 3$ & $49=10$ & 21 & $56=11$ & 18 & $4=8$ \\
\hline LV ESV (mLnn') & 247 & $x=6$ & 274 & $23=6$ & 363 & $x=7$ & 48 & $22=6$ & 295 & $36=8$ & 393 & $20=7$ & $\infty$ & $24=14$ & 183 & $20=7$ & 21 & $22=5$ & 18 & $77=4$ \\
\hline \multicolumn{21}{|l|}{ Bplarex ${ }^{2}$} \\
\hline LV EOV (mLAm) & 29 & $Q=10$ & 30 & $s=0$ & 34 & $B=11$ & 34 & $40=6$ & 45 & $54=9$ & 82 & $45=7$ & s & $2=0$ & 18 & $43=7$ & 38 & $50=x$ & 48 & $\infty 0=7$ \\
\hline LV ESV (mUnt?) & 29 & $24 \pm 5$ & 39 & $\eta \pm 4$ & 34 & $22 \pm 5$ & 34 & $18 \pm 4$ & 45 & $2 x \neq 5$ & 82 & $16 \pm 3$ & 6 & $n=4$ & 196 & $15 \pm 3$ & 38 & $18=4$ & 48 & $y=3$ \\
\hline
\end{tabular}

adalah menggunakan GLS. Hal ini biasanya dinilai dengan metode speckle tracking echocardiography (STE). Pada 2DE, peak GLS menggambarkan panjang relatifperubahan panjang miokardium Vki relatif antara fase akhir-diastole dan akhir-sistol:

\section{GLS $(\%)=($ MLs - MLd $) /$ MLd,}

dimana ML adalah panjang miokard pada akhir sistol (MLs) dan akhir-diastole(MLd). Karena nilai MLs lebih kecil dari MLd, peak GLS memberikan angka negatif. Untuk menghindarkan kebingunan, direkomendasikan bahwa semua referensi terhadap perubahan strain secara spesifik menjelaskan kenaikan atau penurusan dalam nilai absolut dari strain tersebut.
Setelah mengoptimalkan kualitas gambar, memaksimalkan frame rate, dan meminimalkan foreshortening, yang semuanya penting untuk mengurangi variabilitas pengukuran, pengukuran GLS harus dibuat dalam tiga standar pandangan apikal dan dirata-rata hasilnya. Pengukuran dimulai dengan dari pengambilan pandangan APLAX untuk mengidentifikasi penutupan dan pembukaan dari katup aorta menggunakan modalitas M-mode. Apabila pelacakan regional miokardial tampak tidak optimal pada dua atau lebih area miokard pada satu pandangan, maka pemeriksaan GLS sebaiknya tidak dilakukan. Pada keadaan tersebut bisa dilakukan metode atau analisa untuk menilai fungsi Vki.

Dikarenakan terdapat perbedaan atau variabilitas perangkat lunak pada penilaian GLS menggunakan 


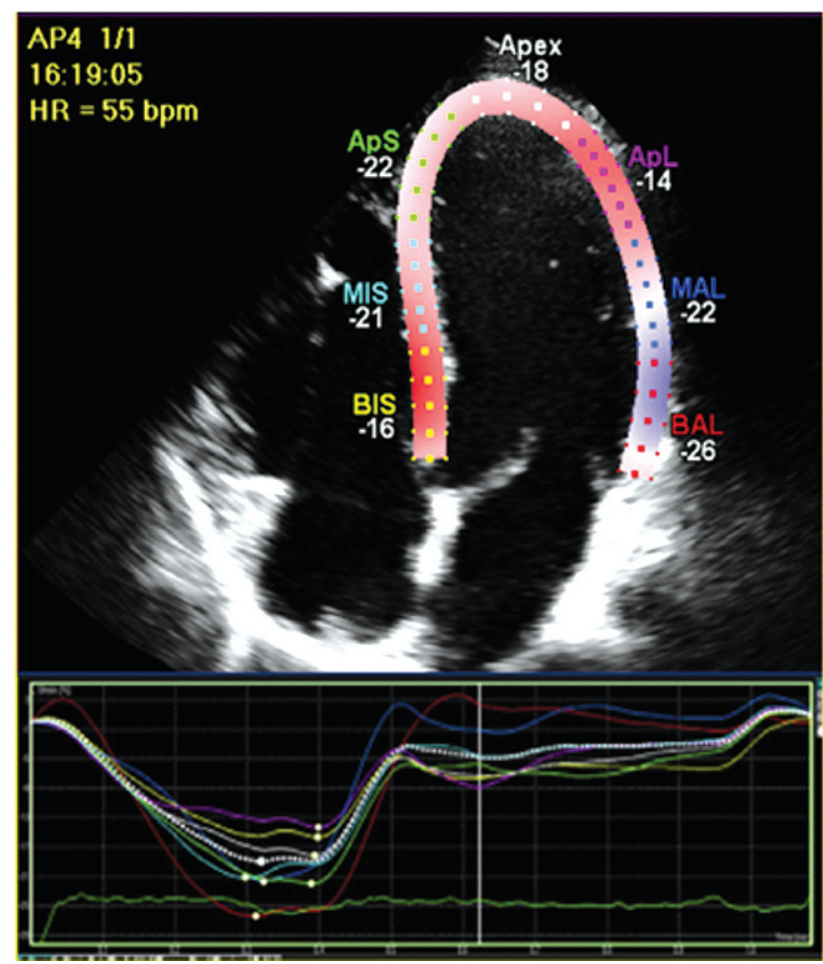

Gambar 3. Pengukuran fungsi sistolik Vki dengan strain (speckle tracking) alat dari vendor yang berbeda serta faktor usia dan kondisi pengisian, maka disarankan penilaian GLS secara serial menggunakan alat dari vendor yang sama atau perangkat lunak yang sama.

Data yang tersedia saat ini adalah pengukuran GLS dari dinding tengah Vki yang dinilai cukup baik untuk digunakan sebagai nilai prediktif pada pasien secara umum terhadap fungsi Vki saat istirahat. Selain itu GLS dapat juga dipakai pada pasien untuk memprediksi fungsi Vki paska operasi katup.

Meskipun variabilitas antar perangkat lunak dan vendor cukup besar, sebagai panduan, nilai peak GLS pada kisaran -20\% dikategorikan normal. Meski demikian, wanita memiliki nilai kisaran GLS yang lebih tinggi dan nilai GLS akan berkurang seiring dengan bertambahnya usia.

\section{Daftar Pustaka}

1. Lang RM,Badano LP, Mor-Avi V, Afilalo J, Amstrong A et al. J Am Soc Echocardiogr 2015;28:1-39

2. Anderson B. Echocardiography: normal examination and echocardiographic measurements $2^{\text {nd }}$ revised edition, Cardiotext, 2007 